ORIGINAL ARTICLE

\title{
Trends in postcoronary artery bypass graft sternal wound dehiscence in a provincial population
}

\author{
Christopher Doherty MPH MD1, Duncan Nickerson MD¹, Danielle A Southern MSc ${ }^{2,3}$, Teresa Kieser MD ${ }^{4,5}$,

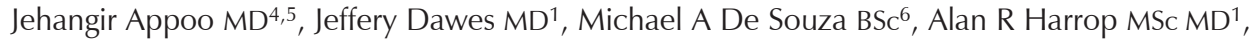 \\ Doreen Rabi MSc MD ${ }^{2,3,7}$; for the Alberta Provincial Project for Outcome Assessment in \\ Coronary Heart Disease (APPROACH) Investigators
}

\begin{abstract}
C Doherty, D Nickerson, DA Southern, et al; for the Alberta Provincial Project for Outcome Assessment in Coronary Heart Disease (APPROACH) Investigators. Trends in postcoronary artery bypass graft sternal wound dehiscence in a provincial population. Plast THERAPEUTIC Surg 2014;22(3):196-200.

BACKGROUND: It appears that the medical profile of patients undergoing coronary artery bypass graft (CABG) surgery has changed. The impact of this demographic shift on CABG outcomes, such as sternal wound dehiscence, is unclear.

OBJECTIVES: To quantify the incidence and trends of sternal wound dehiscence, quantify the demographic shift of those undergoing CABG and identify patient factors predictive of disease.

METHODS: A prospective analysis was performed on a historical cohort of consecutive patients who underwent CABG (without valve replacement) in Alberta between April 1, 2002 and November 30, 2009. The incidence and trends of sternal wound dehiscence were determined. In addition, the trend of the mean Charlson index score and European System for Cardiac Operative Risk Evaluation (EuroSCORE) (capturing patient comorbidities) was analyzed. Univariable analysis and multivariable models were performed to determine factors predictive of wound dehiscence.

RESULTS: A total of 5815 patients underwent CABG during the study period. The incidence proportion of sternal wound dehiscence in Alberta was $1.86 \%$ and the incidence rate was 1.98 cases per 100 person-years. Although both the EuroSCORE and Charlson scores significantly increased over the study period, the incidence of sternal wound dehiscence did not change significantly. Factors predictive of sternal wound dehiscence were diabetes (OR 2.97 [95\% CI 1.73 to 5.10]), obesity (OR 1.55 [95\% CI 1.05 to 2.27]) and female sex (OR 1.90 [95\% CI 1.26 to 2.87]). CONCLUSIONS: The incidence proportion of sternal wound dehiscence in Alberta was comparable with the incidence previously published in the literature. While patients undergoing CABG had worsening medical profiles, the incidence of sternal wound dehiscence did not appear to be increasing significantly.
\end{abstract}

Key Words: Deep sternal wound infection; Sternal wound dehiscence

Coronary artery bypass grafting (CABG) is a common procedure for the treatment of coronary artery disease. Over a five-year period, 774,881 isolated CABG procedures were recorded in the Society of Thoracic Surgeons National Audit Cardiac Surgery Database in the United States (1). Sternal wound dehiscence following mid-line sternotomy approach for CABG can result in significant morbidity and mortality (5\% to 20\%) (2). Despite significant sequelae from developing wound dehiscence, this complication is relatively uncommon, with incidence commonly reported to be between $0.4 \%$ and $4 \%(1,3-12)$.

As described by Pairolero and Arnold (13), sternal wound dehiscence can be classified as type I (postoperative days 1 to 3), type II (within the first two to three weeks postoperatively) and type III (one year to several years postoperatively). Type I infections are generally superficial in nature, with the possibility of progressing to type II

\section{Les tendances de déhiscence sternale après un pontage aortocoronarien au sein d'une population provinciale}

HISTORIQUE : Il semble que le profil médical des patients qui subissent un pontage aortocoronarien (PAC) a changé. On ne connaît pas les effets de ce changement démographique sur les résultats des PAC, tels que la déhiscence sternale.

OBJECTIF: Quantifier l'incidence et les tendances de déhiscence sternale, quantifier le changement démographique des personnes qui subissent un PAC et cerner les facteurs liés aux patients qui sont prédictifs de maladie.

MÉTHODOLOGIE : Les chercheurs ont effectué une analyse prospective auprès d'une cohorte historique de patients consécutifs qui avaient subi un PAC (sans remplacement valvulaire) en Alberta entre le $1^{\text {er }}$ avril 2002 et le 30 novembre 2009. Ils ont déterminé l'incidence et les tendances des déhiscences sternales. Ils ont analysé la tendance de l'indice moyen de Charlson et de l'EuroSCORE (European System for Cardiac Operative Risk Evaluation) (qui saisit les comorbidités des patients). Ils ont utilisé des analyses univariables et des modèles multivariables pour déterminer les facteurs prédictifs d'une déhiscence de la plaie.

RÉSULTATS : Au total, 5815 patients ont subi un PAC pendant la période de l'étude. La proportion de déhiscence sternale en Alberta était de 1,86 \% et le taux d'incidence, de 1,98 cas sur 100 personnes-année. Même si l'EuroSCORE et l'indice de Charlson ont augmenté considérablement pendant la période de l'étude, l'incidence de déhiscence sternale n'a pas changé de manière significative. Le diabète (RC 2,97 [95 \% IC 1,73 à 5,10]), l'obésité (RC 1,55 [95\% IC 1,05 à $2,27]$ ) et le sexe féminin ( $\mathrm{RC} 1,90$ [95 \% IC 1,26 à 2,87]) étaient les facteurs prédictifs de déhiscence sternale.

CONCLUSIONS : La proportion de déhiscence sternale en Alberta était comparable à celle publiée par le passé. Le profil médical des patients qui subissent un PAC s'aggravait, mais l'incidence de déhiscence sternale ne semblait pas augmenter de manière significative.

infections. Type II infections generally require irrigation and debridement, serial dressing changes, and local or regional flap closure. It is inferred that additional procedures such as these result in prolonged length of stay, increase risk to the patient and increased use of hospital resources. Understanding the incidence of sternal wound dehiscence in a given patient population is important for quality control and resource planning.

The patient population undergoing CABG appears to be changing, as evidenced by long-term studies demonstrating that CABG benefits individuals with certain comorbid conditions (such as diabetes and renal failure) compared with angioplasty (14-17). It is believed this has an impact on management protocols - and, therefore, the incidence of sternal wound dehiscence - because individuals undergoing CABG today have proportionately more comorbid conditions than previously studied cohorts.

${ }^{1}$ Section of Plastic Surgery, Department of Surgery; ${ }^{2}$ Department of Community Health Sciences; ${ }^{3}$ Institute for Public Health, University of Calgary; ${ }^{4}$ Libin Cardiovascular Institute of Alberta; ${ }^{5}$ Division of Cardiac Surgery, Department of Surgery; ${ }^{6}$ Department of Biological Sciences;

${ }^{7}$ Department of Medicine, University of Calgary, Calgary, Alberta

Correspondence: Dr Christopher Doherty, HRIC 2A02, 3280 Hospital Drive Northwest, Calgary, Alberta T2N 4N1.

Telephone 403-944-4317, fax 403-270-7307, e-mail cdohert8@uwo.ca 
The purposes of the present study were to determine the incidence of sternal wound dehiscence in a provincial population of patients undergoing CABG over the eight-year period from 2002 to 2009, and to determine which comorbidities predisposed patients to these complications in this cohort. In addition, we aimed to evaluate whether patient comorbidity profiles changed over time.

\section{METHODS}

The present study was a prospective analysis of an historical cohort who underwent CABG in Alberta between April 1, 2002 and November 30, 2009. The Alberta Provincial Project for Outcome Assessment in Coronary Heart Disease (APPROACH) database contains clinical and demographic data on all patients in Alberta undergoing a cardiac revascularization procedure. This database was used to identify consecutive patients $>18$ years of age undergoing CABG during the specified observation period.

Exclusion criteria included patients undergoing CABG with valve replacement, patients undergoing the index surgery outside of Alberta, age $\leq 18$ years and incomplete data. Using unique regional health figures, the cohort of CABG patients identified in APPROACH was linked to provincial administrative health databases to identify the subset of patients diagnosed with sternal wound dehiscence either during their index admission for CABG surgery or in a subsequent admission within one year of CABG surgery.

An administrative data definition for sternal wound dehiscence was developed within the APPROACH database to identify cases. Sternal wound dehiscence is defined as postoperative wound disruption at the mid-line sternotomy site for CABG. This definition was based on International Classification of Diseases codes shown to be effective at identifying sternal wound cases in large databases, as well as previously published definitions by the Centers for Disease Control and Prevention (Georgia, USA) and others (18-20). The definition was tested for accuracy with random chart review (not yet published).

Person-time of observation was calculated for all patients in the cohort. Individuals who developed sternal wound dehiscence or died within one year of CABG no longer contributed to observation time as of the day of the event. The number of cases of wound dehiscence and total person time of observation for the study cohort were used to generate an incidence rate for sternal wound dehiscence. An incidence proportion (number of new cases of sternal wound dehiscence divided by the total number of CABG patients) was also calculated.

Patient characteristics and comorbidities (age, sex, Charlson score, diabetes [insulin and noninsulin dependent], renal failure [dialysis and nondialysis dependent], smoking history, body mass index [BMI], use of one or both internal thoracic arteries for revascularization, New York Heart Association [NYHA] score and time from catheterization to $\mathrm{CABG}$ ) were compared for patients with and without sternal wound dehiscence. $\mathrm{P}$ values were calculated using the $\chi^{2}$ test for proportions and $\mathrm{F}$ test for mean differences.

Backward stepwise logistic regression was performed to determine predictive covariates for sternal wound dehiscence. Age, sex, BMI, NYHA score, renal disease (dialysis and no dialysis), diabetes (insulin and no insulin), smoking status and Charlson score were included in the model. The backward stepwise method had the constraint of $\mathrm{P}<0.05$; ORs and Cls were included for the final models. Data regarding the use of internal thoracic artery harvest (bilateral, left or right) were only available for one section of the provincial population, named 'Region A'. The other was named 'Region B'. Therefore, a Region A subanalysis was performed with a covariate for use of one or both internal thoracic arteries added to the model described above.

Trends over time in incidence of sternal wound dehiscence, mean Charlson index score and mean European System for Cardiac Operative Risk Evaluation score (EuroSCORE) were examined and tested for significance. The Charlson index is a validated score capturing patient factors that predict one-year mortality. The range of clinical characteristics considered with the Charlson index is broad,

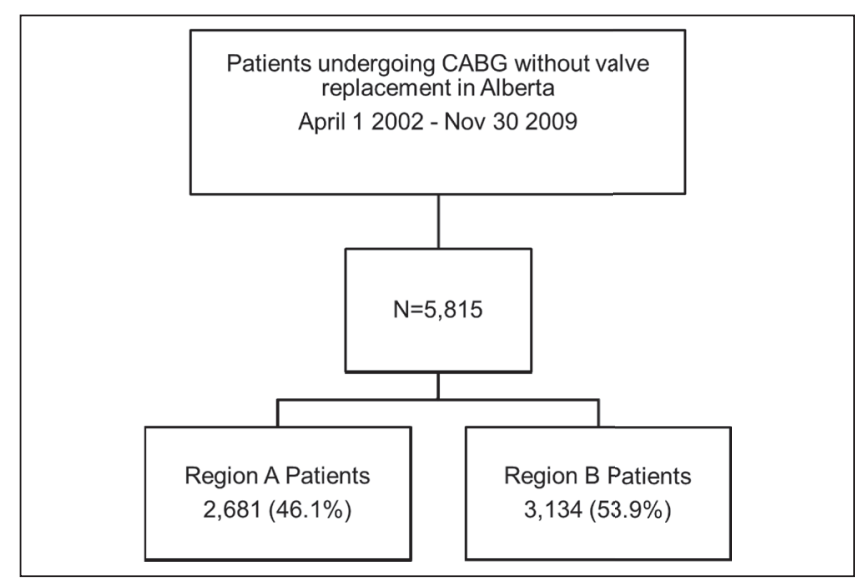

Figure 1) Consort diagram. CABG Coronary artery bypass graft; Nov November

including measures of cardiac, pulmonary, renal and metabolic illness (21). Similarly, the EuroSCORE is a validated comorbidity index used to predict mortality, but is more specific to the cardiac surgery population (22).

Statistical analysis was performed using SAS version 9.2 (SAS Institute, USA). The present study was approved by the University of Calgary Conjoint Health Research Ethics Board (Calgary, Alberta).

\section{RESULTS}

Between April 1, 2002 and November 30, 2009, 5815 patients underwent CABG in Alberta (Figure 1), of whom 108 were diagnosed with sternal wound dehiscence within one year of their original CABG surgery. This represents an incidence proportion of $1.86 \%$ for sternal wound dehiscence. There were 5463.82 person-years of observation contributed, resulting in an incidence rate of sternal wound dehiscence of 1.98 cases per 100 person-years of observation.

Patient characteristics and comorbidities are summarized in Table 1. Univariate analysis demonstrated that mean age in the two groups was comparable. Patients with sternal wound dehiscence were more likely to be female, obese and diabetic, and have a higher mean BMI, NYHA class and Charlson score. There was no difference in mean wait time from catheterization to CABG for individuals with sternal wound dehiscence versus those without.

Multivariable logistic regression was performed to determine which covariables predicted sternal wound dehiscence. Variables included in the initial model were age, sex, BMI, renal disease, diabetes, NYHA class, smoking status and Charlson score. Stepwise backward regression was performed to refine the model $(\mathrm{P}<0.05)$. Factors found to be predictive of sternal wound dehiscence were female sex, diabetes (insulin and noninsulin dependent) and BMI $\geq 30 \mathrm{~kg} / \mathrm{m}^{2}$ (Table 2).

A subanalysis of Region A (for which there were data pertaining to use of the internal thoracic arteries in the revascularization procedure) was conducted to determine whether bilateral internal thoracic artery harvesting for revascularization was an independent risk factor for dehiscence. Using backward stepwise regression modelling, bilateral internal thoracic artery donor vessels were not found to be a statistically significant predictor of sternal wound dehiscence such as those outlined in Table 3.

Trends over time for sternal wound dehiscence, as well as preoperative Charlson index and EuroSCOREs, are shown in Figures 2 and 3. These figures show a cyclical variation in incidence of wound dehiscence; however, this was not found to be significant. The mean Charlson score was significantly higher from trough to peak (2004 to 2006, 1.37 versus 2.38; $\mathrm{P}<0.0001$ ) as was the EuroSCORE (2004 to $2008,3.25$ versus $4.25 ; \mathrm{P}<0.0001$ ). Note that a higher score represents more comorbid conditions for a given patient. 
TABLE 1

Patient characteristics

\begin{tabular}{|c|c|c|c|}
\hline Characteristic & $\begin{array}{c}\text { Dehiscence } \\
(n=108)\end{array}$ & $\begin{array}{c}\text { No dehiscence } \\
(n=5707)\end{array}$ & $\mathbf{P}$ \\
\hline Age, years, mean \pm SD & $66.4 \pm 10.0$ & $66.3 \pm 10.2$ & 0.89 \\
\hline Age group, years & & & 0.99 \\
\hline$<30$ & $0(0)$ & $3(0.1)$ & \\
\hline $30-39$ & $0(0)$ & $31(0.5)$ & \\
\hline $40-49$ & $6(5.6)$ & $341(6.0)$ & \\
\hline $50-59$ & $23(21.3)$ & $1203(21.1)$ & \\
\hline $60-69$ & $38(35.2)$ & 1854 (32.5) & \\
\hline $70-79$ & $35(32.4)$ & $1843(32.3)$ & \\
\hline $80-89$ & $6(5.6)$ & $429(7.5)$ & \\
\hline$>90$ & $0(0)$ & $2(0.04)$ & \\
\hline Female sex & $35(32.4)$ & $1084(19.0)$ & 0.001 \\
\hline Smoker & & & 0.84 \\
\hline Current & $25(23.2)$ & 1114 (19.5) & \\
\hline Former & $44(40.7)$ & 2344 (41.1) & \\
\hline Never & $20(18.5)$ & $1264(22.2)$ & \\
\hline Unknown & 19 (17.6) & $985(17.3)$ & \\
\hline $\mathrm{BMI}, \mathrm{kg} / \mathrm{m}^{2}$, mean $\pm \mathrm{SD}$ & $30.7 \pm 5.5$ & $28.8 \pm 4.8$ & 0.0001 \\
\hline BMI grouping, $\mathrm{kg} / \mathrm{m}^{2}$ & & & 0.0001 \\
\hline$<20$ & $2(1.9)$ & $80(1.4)$ & \\
\hline $20-25$ & $12(11.1)$ & $1139(20.0)$ & \\
\hline $25-30$ & $35(32.4)$ & $2372(41.6)$ & \\
\hline$>30$ & $53(49.1)$ & $2033(35.6)$ & \\
\hline Missing data & $6(5.6)$ & $83(1.5)$ & \\
\hline Renal failure & & & 0.48 \\
\hline Dialysis & $3(2.8)$ & $83(1.5)$ & \\
\hline No dialysis & $9(8.3)$ & $419(7.3)$ & \\
\hline Diabetes & & & $<0.0001$ \\
\hline Insulin dependent & $19(17.6)$ & $415(7.3)$ & \\
\hline Non-insulin dependent & $36(33.3)$ & $1397(24.5)$ & \\
\hline \multicolumn{2}{|c|}{ New York Heart Association class } & & 0.03 \\
\hline I & $8(7.4)$ & $743(13.0)$ & \\
\hline II & $27(25.0)$ & $1140(20.0)$ & \\
\hline III & $14(13.0)$ & $427(7.5)$ & \\
\hline IV & $4(3.7)$ & $111(1.9)$ & \\
\hline Not entered & $63(58.3)$ & $4029(70.6)$ & \\
\hline Charlson index score & & & 0.002 \\
\hline 0 & $9(8.3)$ & $991(17.4)$ & \\
\hline 1 & $19(17.6)$ & $1298(22.7)$ & \\
\hline 2 & $16(14.8)$ & $1040(18.2)$ & \\
\hline 3 & $14(13.0)$ & $825(14.5)$ & \\
\hline 4 & $16(14.8)$ & $587(10.3)$ & \\
\hline 5 & $14(13.0)$ & $364(6.4)$ & \\
\hline 6 & $7(6.5)$ & $211(3.7)$ & \\
\hline$\geq 7$ & $13(12.0)$ & $391(6.9)$ & \\
\hline $\begin{array}{l}\text { Days from catheterization } \\
\text { to } C A B G \text {, mean } \pm S D\end{array}$ & $48.2 \pm 66.1$ & $57.1 \pm 73.7$ & 0.21 \\
\hline
\end{tabular}

Data presented as $n$ (\%) unless otherwise indicated. BMI Body mass index; $C A B G$ Coronary artery bypass grafting

\section{DISCUSSION}

The purpose of the present population-based study was to quantify the incidence and trend of postoperative sternal wound dehiscence in patients undergoing $\mathrm{CABG}$ surgery and to identify changing patient characteristics between 2002 and 2009. We also aimed to determine patient factors that were predictive of sternal wound dehiscence. The present study served as an opportunity for quality control and public health monitoring within this provincial population.

The incidence rate of sternal wound dehiscence in our population was 1.98 per 100 person-years. Incidence rate as an outcome measure
TABLE 2

Multivariable logistic regression model for the Alberta population

\begin{tabular}{lc}
\hline Variable & OR (95\% CI) \\
\hline Female & $1.90(1.26-2.87)$ \\
Diabetes (insulin) & $2.97(1.73-5.10)$ \\
Diabetes (noninsulin) & $1.76(1.14-2.71)$ \\
Body mass index ${ }^{*} 30 \mathrm{~kg} / \mathrm{m}^{2}$ & $1.55(1.05-2.27)$ \\
\hline${ }^{*}$ Reference group body mass index $=20 \mathrm{~kg} / \mathrm{m}^{2}$ to $25 \mathrm{~kg} / \mathrm{m}^{2}$
\end{tabular}

TABLE 3

Multivariable logistic model for Region A

\begin{tabular}{ll}
\hline Variable & OR $(95 \% \mathrm{Cl})$ \\
\hline Female & $2.17(1.29-3.65)$ \\
Body mass index $^{*} \geq 30 \mathrm{~kg} / \mathrm{m}^{2}$ & $1.77(1.08-2.92)$ \\
Charlson score $^{\dagger}=4$ & $2.38(1.21-4.67)$ \\
Charlson score $^{\dagger}=5$ & $2.28(1.00-5.19)$ \\
\hline
\end{tabular}

Reference groups: *Body mass index $=20 \mathrm{~kg} / \mathrm{m}^{2}$ to $25 \mathrm{~kg} / \mathrm{m}^{2} ;{ }^{+}$Charlson score $=0$

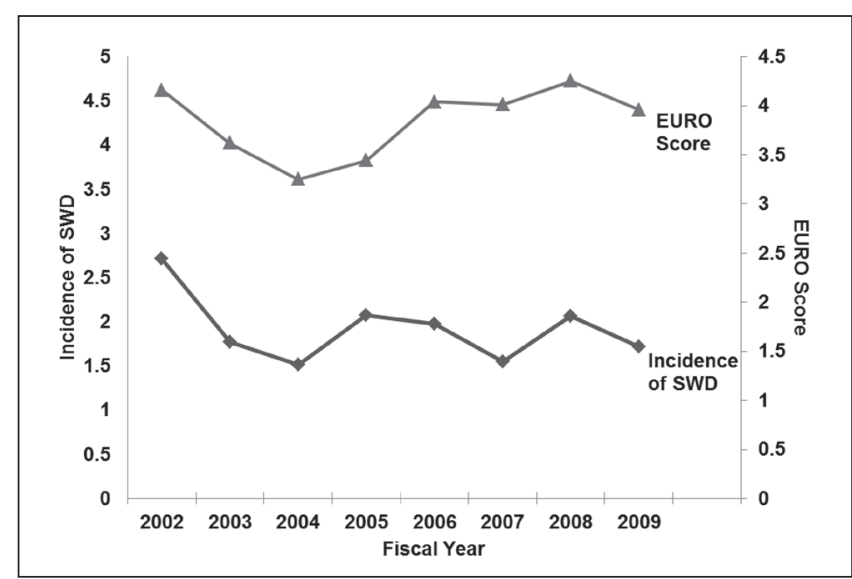

Figure 2) Incidence of sternal wound dehiscence (SWD) and European System for Cardiac Operative Risk Evaluation (EuroSCORE)

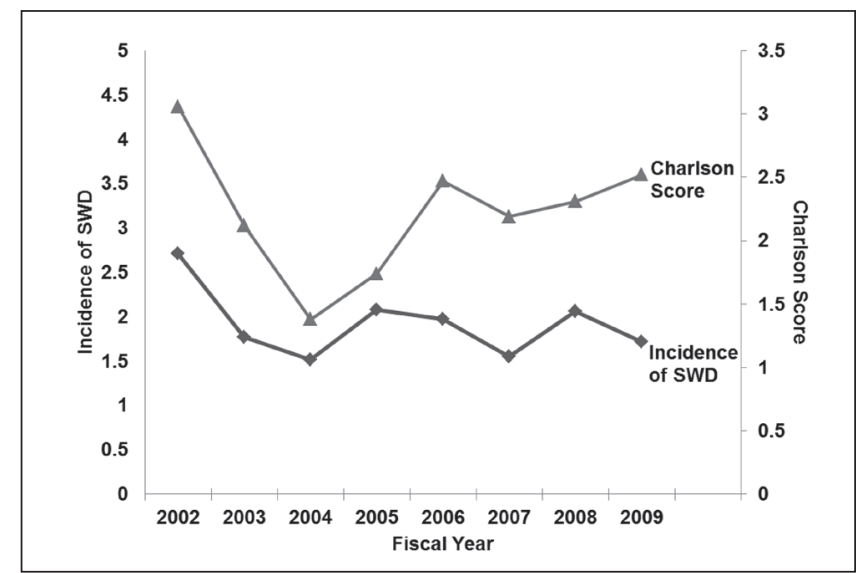

Figure 3) Incidence of sternal wound dehiscence (SWD) and Charlson score

is presented to account for competing risks in a high-risk population and because the follow-up for patients undergoing CABG started at different times between 2002 and 2009. On the other hand, the outcome incidence proportion, commonly reported in the literature, represents the number of new cases of sternal wound dehiscence divided by the total population at risk in a given time. The incidence proportion for sternal wound dehiscence in our population was $1.86 \%$.

A cyclical variation in the incidence of sternal wound dehiscence between 2002 and 2009 was observed. Although this variation was 
nonsignificant, several possible reasons to explain this finding were considered. A sensitivity analysis was performed to determine whether the introduction of a regional perioperative wound protocol in 2007 and 2008 had any effect on dehiscence rates; however, this intervention was not found to be significant. Changes in surgical volume were examined because increased volume has been shown to decrease complications (23-25). There was no clear correlation with the cyclical variation in sternal wound dehiscence and surgical volume. Regional or province-wide monitoring practices were also analyzed. No known changes in coding or monitoring for sternal wound dehiscence occurred during the time period. The International Classificatioon of Diseases (ICD), Ninth Revision coding system was changed to the ICD 10 system in 2002 and, thus, this transition was not believed to have impacted rates over time. Overall, it was believed that when observed over the course of nearly a decade, the incidence of sternal wound dehiscence will exhibit some nonsignificant variation, an important consideration when monitoring monthly, quarterly or yearly health outcome indicators.

Multivariable analysis revealed that female sex, diabetes (insulin and noninsulin dependent) and $\mathrm{BMI} \geq 30 \mathrm{~kg} / \mathrm{m}^{2}$ were predictive of sternal wound dehiscence in our population. This both supports and conflicts with the work of various other investigators. Determining exactly which factors are predictive of wound dehiscence appears to be an elusive task when one reviews the literature, as evidenced by conflicting results from multiple different analyses. This point is aptly highlighted in the discussion of the study by Bitkover and Gardlund (11), which demonstrated that contradictory results are ubiquitous from both well and poorly performed studies, even for factors routinely reported as being predictive of sternal wound dehiscence such as diabetes, smoking, age, obesity and renal failure. Given the apparent variability of predictive factors of disease from centre to centre, the importance of performing local studies and quality assurance monitoring is stressed to determine which factors are important in a given population.

Matsa et al (26) and Lev-Ran et al (27) also showed an increased incidence of sternal wound dehiscence in patients who were obese, female and diabetic, and recommended avoidance of the use of bilateral internal thoracic artery in this specific population. Other work has shown obesity and diabetes to be risk factors for the development of sternal wound dehiscence $(1,4,11,28,29)$.

It was hypothesized that the overall health of patients undergoing CABG had changed within our population after 2004. Previous work has shown that the ratio of percutaneous coronary intervention to CABG did not change significantly in Alberta up to that point (30). Following the publication of long-term studies described earlier, however, it was observed that management strategies shifted favouring CABG for patients with more comorbid conditions. In an Australian population undergoing CABG, Dinh et al (31) reported an increased incidence of hypertension, respiratory disease and left main coronary artery disease over a time frame similar to our study. Fakih et al (32) observed a correlation between changing patient characteristics and an increasing sternal wound infection rate. In particular, they showed that the incidence of specific diseases (peripheral vascular disease and congestive heart failure) increased over the study period; however, a global comorbidity scale was not used to evaluate the overall health of patients. In contrast, El Bardissi et al (33) reported an increase of diabetes and hypertension in patients undergoing $\mathrm{CABG}$, but with a decrease in sternal wound infection incidence. Again, no global scale was used to capture the overall health of patients undergoing CABG. Our study adds to this body of work in that it found evidence of a significant increase in global comorbidity scores (Charlson index score and EuroSCORE) but a stable rate of sternal wound dehiscence.

Strengths of the present study include the analysis of an entire provincial population, the demonstration of trends in sternal wound dehiscence over an eight-year period in this population and the demonstation of a changing population of patients undergoing CABG. Limitations to the present study included potential loss to follow-up of patients who developed wound dehiscence outside the province. On the other hand, the population undergoing CABG is primarily elderly and unlikely to travel outside the province due to health care and health insurance concerns, thereby minimizing this potential loss to follow-up. Diabetes control was measured based on whether a patient used insulin; therefore, precise glycemic levels were not captured. Other limitations to the study included biases inherent with population-based studies and failure to include some variables predictive of disease.

\section{CONCLUSION}

The incidence proportion of sternal wound dehiscence in our population was $1.86 \%$. Cyclical but nonsignificant trends in incidence were apparent over an eight-year period. Obesity, diabetes and female sex were predictive of disease in this population. The population of patients undergoing $\mathrm{CABG}$ had more comorbid conditions than in the past. Despite this, the incidence of sternal wound dehiscence did not change significantly within our population.

ACKNOWLEDGEMENTS: The authors gratefully acknowledge the cardiac personnel for their diligence in data collection and entry: Foothills Medical Centre; Royal Alexandra Hospital; and the University of Alberta Hospital. Members of the APPROACH Clinical Steering Committee: Edmonton - Dr Ross Tsuyuki (chair); Dr Wayne Tymchak; Dr Michelle Graham; Dr Arvind Koshal; Dr Neil Brass: Calgary - Dr Micheal Curtis; Dr William A Ghali; Dr Merril L Knudtson; Dr Andrew Maitland; Dr L Brent Mitchell and Dr Mouhieddin Traboulsi. The authors also thank Drs Steven Meyer and David Ross for their thoughts and expert consultation on this project.

FUNDING SOURCES: This study was funded through the University of Calgary Surgical Research Development Fund.

\section{REFERENCES}

1. Shahian DM, O'Brien SM, Filardo G, et al. The Society of Thoracic Surgeons 2008 Cardiac Surgery Risk Models: Part 1 Coronary artery bypass grafting. Ann Thorac Surg 2009;88:2-22.

2. Landes G, Harris PG, Sampalis JS, et al. Outcomes in the management of sternal dehiscence by plastic surgery. Ann Plast Surg 2007;59:659-66.

3. Loop FD, Lytle BW, Cosgrove DM, et al. Sternal wound complications after isolated coronary artery bypass grafting. Ann Thorac Surg 1990;49:179-86.

4. Risnes I, Abdelnoor M, Almdahl SM, et al. Mediastinitis after coronary artery bypass grafting risk factors and long-term survival. Ann Thorac Surg 2010;89:1502-10.

5. Abboud CS, Barsanti S, Baltar VT. Risk factors for mediastinitis after cardiac surgery. Ann Thorac Surg 2004;77:676-83.

6. Milano CA, Kesler K, Archibald N, et al. Mediastinitis after coronary artery bypass grafting. Circulation 1995;92:2245-51.

7. Braxton JH, Marrin CA, McGrath PD, et al. 10-year follow-up of patients with and without mediastinitis. Semin Thorac Cardiovasc Surg 2004;16:70-6.

8. Borger MA, Rao V, Weisel RD, et al. Deep sternal wound infection: Risk factors and outcomes. Ann Thorac Surg 1998;65:1050-6.

9. Stahle E, Tammelin A, Bergstrom R, et al. Sternal wound complications - incidence, microbiology and risk factors. Eur J Cardiothorac Surg 1997;11:1146-53.

10. Toumpoulis IK, Anagnostopoulos CE, Derose Jr JJ, et al. The impact of deep sternal wound infection on long-term survival after coronary artery bypass grafting. Chest 2005;127:464-71.

11. Bitkover CY, Gardlund B. Mediastinitis after cardiovascular operations: A case-control study of risk factors. Ann Thorac Surg 1998;65:36-40.

12. Braxton JH, Marrin CA, McGrath PD, et al. Mediastinitis and long-term survival after coronary artery bypass graft surgery. Ann Thorac Surg 2000;70:2004-7.

13. Pairolero PC, Arnold PG. Management of infected median sternotomy wounds. Ann Thorac Surg 1986;42:1-2. 
14. Malenka DJ, Leavitt BJ, Hearne MJ, et al. Comparing long-term survival of patients with multivessel coronary disease after CABG or PCI: Analysis of BARI-like patients in northern New England. Circulation 2005;112(9 Suppl):I371-6.

15. Hannan EL, Racz MJ, Walford G, et al. Long-term outcomes of coronary-artery bypass grafting versus stent implantation. N Engl J Med 2005;352:2174-83.

16. Alderman EL, Andrews K, Bost J, et al. Comparison of coronary bypass surgery with angioplasty in patients with multivessel disease. N Engl J Med 1996;335:217-25.

17. Serruys PW, Ong AT, van Herwerden LA, et al. Five-year outcomes after coronary stenting versus bypass surgery for the treatment of multivessel disease: The final analysis of the Arterial Revascularization Therapies Study (ARTS) randomized trial. J Am Coll Cardiol 2005;46:575-81.

18. Hebden J. Use of ICD 9-CM coding as a case finding method for sternal wound infections after $\mathrm{CABG}$ procedures. Am J Infect Control 2000;28:202-3.

19. Garner JS, Jarvis WR, Emori TG, et al. CDC definitions for nosocomial infections 1988. Am J Infect Control 1988;16:128-40.

20. El Oakley RM, Wright JS. Postoperative mediastinitis: Classification and management. Ann Thorac Surg 1996;61:1030-60.

21. Charlson ME, Pompei P, Ales KL, et al. A New method of classifying prognostic comorbidity in longitudinal studies: Development and validation. J Chron Dis 1987;40:373-83.

22. Nashef SAM, Roques F, Michel P, et al. European Systemic for Cardiac Operative Risk Evaluation (EuroSCORE).

Eur J Cardiothorac Surg 1999;16:9-13.

23. Drolet S, MacLean AR, Myers RP, et al. Elective resection of colon cancer by high-volume surgeons is associated with decreased morbidity and mortality. J Gastrointest Surg 2011;15:541-50.

24. Rogers SO Jr, Wolf RE, Zaslavsky AM, et al. Relation of surgeon and hospital volume to processes and outcomes of colorectal cancer surgery. Ann Surg 2006;244:1003-11.
25. Karanicolas PJ, Dubois L, Colquhoun PH, et al. The more the better? The impact of surgeon and hospital volume on in-hospital mortality following colorectal resection. Ann Surg 2009;249:954-9.

26. Matsa M, Paz Y, Gurevitch J, et al. Bilateral skeletonized internal thoracic artery grafts in patients with diabetes mellitus. J Thorac Cardiovasc Surg 2001;121:668-74.

27. Lev-Ran O, Mohr R, Pevni D, et al. Bilateral internal thoracic artery grafting in diabetic patients: Short-term and long-term results of a 515 patient series. J Thorac Cardiovasc Surg 2004;127:1145-50.

28. Prasad US, Walker WS, Sang CT, et al. Influence of obesity on the early and long term results for coronary artery disease. Eur J Cardiothorac Surg 1991;5:67-72.

29. Birkmeyer NJ, Charlseworth DC, Hernandez F, et al. Obesity and risk of adverse outcomes associated with coronary artery bypass surgery. Circulation 1998;97:1689-94.

30. Hassan A, Newman A, Ko D, et al. Increasing rates of angioplasty vs. bypass surgery in Canada, 1994-2005. Am Heart J 2010;160:958-64.

31. Dinh DT, Lee GA, Billah B, et al. Trends in coronary artery bypass grafting in Victoria, 2001-2006: Findings from the Australasian Society of Cardiac and Thoracic Surgeons database project. Austral Med J 2008;188:214-7.

32. Fakih MG, Sharma M, Khatib R, et al. Increase in the rate of sternal surgical site infection after coronary artery bypass graft: A marker of higher severity of illness. Infect Control Hospital Epidemiol 2007;28:655-60.

33. El Bardissi AW, Aranki SF, Sheng S, et al. Trends in isolated coronary artery bypass grafting: An analysis of the Society of Thoracic Surgeons adult cardiac surgery database. J Thorac Cardiovasc Surg 2012;143:273-81. 